\title{
In situ thermolysis of Pt-carbonyl complex to form supported clean Pt nanoclusters with enhanced catalytic performance
}

\author{
Guijuan Wei ${ }^{1,2}$, Xixia Zhao ${ }^{1}$, Changhua An ${ }^{1,2^{*}}$, Junxue Liu ${ }^{1}$, Zhaojie Wang ${ }^{1}$, Kun Du ${ }^{1}$ and Jun Zhang ${ }^{1 *}$
}

\begin{abstract}
Clean Pt nanoclusters with a diameter of 1.0-2.4 nm, supported on reduced graphene oxide (rGO) nanosheets, were successfully synthesized by simple in situ thermolysis of a Pt-carbonyl complex. The supported Pt nanoclusters are in an electron-deficient state because of the electron transfer between the nanoclusters and the rGO sheets. The as-prepared Pt-1 nm/rGO shows high catalytic activity for the $100 \%$ selective hydrogenation of nitrobenzene, with the turnover frequency (TOF) reaching $975.4 \mathrm{~h}^{-1}$ at $25^{\circ} \mathrm{C}$ and $1 \mathrm{~atm}$. This number is higher than the previously reported value for the heterogeneously catalyzed hydrogenation of nitrobenzene. The proposed process follows a direct hydrogenation mechanism, as is revealed by the analyses of the intermediate products. This work presents a facile and effective synthetic approach for achieving highly efficient nanocatalysts, and can be extended to obtain other metal catalysts with ultra-small sizes and excellent performance.
\end{abstract}

Keywords: hydrogenation, nanoclusters, reduced graphene oxide, platinum, catalyst

\section{INTRODUCTION}

Aniline (AN), an important chemical raw material, is mainly used in the organic chemicals industry, e.g., in the synthesis of resins, dyes, and pharmaceuticals. AN is typically prepared by the hydrogenation of nitrobenzene (NB) in the liquid or vapor phase, and the latter is usually performed at $473 \mathrm{~K}$ over copper-based catalysts [1], which often suffers from low selectivity and poison resistance [2]. Noble metal (such as Pd, Pt, Ru) catalysts have been developed and demonstrated to show good performance in the hydrogenation of NB in the liquid-phase [3-6]. In such systems, harsh reaction conditions, e.g., higher system temperature and pressure are commonly required [7-11]. Other issues associated with the toxic organic solvents and poor selectivity of the catalyst also exist. Furthermore, undesirable by-products, such as nitrosobenzene (NSB), $\mathrm{N}$-phenylhydroxylamine (PHA) and azoxybenzene (AOB) are inevitably produced $[12,13]$. Therefore, it is highly desirable to develop green catalysts that simultaneously possess high activity and selectivity at room temperature and atmospheric pressure.

Carbon materials, particularly graphene and carbon nanotubes, which have the same $\mathrm{sp}^{2}$ hybridization state, are promising candidates for the development of high-performance catalysts because of their unique structures with a large specific surface area [14-18]. Liu and co-workers [19] prepared Pt NPs supported on multiwall carbon nanotubes (MWCNTs), which exhibited excellent activity for the solvent-free hydrogenation of NB to AN at a pressure of 2.0 MPa. Nie et al. [20] used Pt/reduced graphene oxide (rGO) nanocomposites as the catalysts for the hydrogenation of nitroarenes, which showed higher catalytic activity than Pt/CNTs at 1.0 MPa. Nevertheless, these catalytic systems are not efficient enough and require harsh conditions.

Pt nanoparticles (NPs) are known to be effective and environmentally friendly catalysts, and have attracted tremendous attention in the past few decades. They are frequently employed to catalyze a wide range of oxidation and hydrogenation reactions [21-24]. Unfortunately, the low abundance of platinum in nature and high cost restricts its widespread application. A significant enhancement in

\footnotetext{
${ }^{1}$ State Key Laboratory of Heavy Oil Processing, College of Science and College of Chemical Engineering, China University of Petroleum, Qingdao 266580, China

${ }^{2}$ Tianjin Key Laboratory of Organic Solar Cells and Photochemical Conversion, College of Chemistry and Chemical Engineering, Tianjin University of Technology, Tianjin 300384, China

*Corresponding authors (emails: anchh@upc.edu.cn (An C); zhangj@upc.edu.cn (Zhang J))
} 
the catalytic efficiency and recycle durability of platinum is of paramount importance in reducing its use. Nanoclusters with a high volume/surface ratio and quantum effect have been proven to be efficient catalysts in various useful reactions. To date, several synthetic approaches have been developed to fabricate these small nanoparticles, including solution-phase reduction, gas-phase synthesis, and the ligand-assisted approach [25-29]. However, the fabrication of small nanoparticles is still challenging because of their severe aggregation, wide size distribution, low output, and low activity. Furthermore, these methods involve poor control of the particle size distribution.

In this work, we presented a detailed study on in situ formed Pt nanoclusters on rGO by thermally decarbonylating their carbonyl compounds. The sizes of the Pt nanoclusters can be easily controlled by fine tuning the reaction conditions. The effect of the cluster size on the catalytic performance for NB hydrogenation was systematically investigated. The results indicated that the Pt- $1 \mathrm{~nm} / \mathrm{rGO}$ nanocatalysts exhibited the highest catalytic performance, including a high conversion ratio, excellent selectivity, and good durability under ambient conditions $\left(25^{\circ} \mathrm{C}, 1 \mathrm{~atm}\right)$.

\section{EXPERIMENTAL SECTION}

\section{Materials}

$\mathrm{Na}_{2} \mathrm{PtCl}_{6} \cdot 6 \mathrm{H}_{2} \mathrm{O}$ was purchased from Shanghai Aladdin Chemistry Co. Ltd, China. $\mathrm{CH}_{3} \mathrm{COONa}$, graphite powder, $\mathrm{H}_{2} \mathrm{O}_{2}$, and $\mathrm{H}_{2} \mathrm{SO}_{4}$ were purchased from the Sinopharm Chemical Reagent Co. Ltd. Methanol and isopropanol were purchased from Xilong Chemical Co. Ltd. CO and $\mathrm{N}_{2}$ were purchased from Qingdao Tianyuan Gas Co. Ltd., and $\mathrm{KMnO}_{4}$ was obtained from Beijing Chemical Reagent. All the reagents were analytical grade and used as received.

\section{Preparation of graphene oxide}

Graphene oxide (GO) was synthesized via a modified Hummer's method [30]. In a typical procedure, graphite (1 g) and concentrated sulfuric acid $(23 \mathrm{~mL})$ were mixed in a 250-mL round-bottom flask, placed in an ice-water bath, and stirred for $15 \mathrm{~min}$. Then, $\mathrm{KMnO}_{4}(3 \mathrm{~g})$ was slowly added into the suspension and stirred for $1 \mathrm{~h}$. The flask was transferred into an oil bath at $35^{\circ} \mathrm{C}$ and stirring was continued for an additional $30 \mathrm{~min}$, then $46 \mathrm{~mL}$ deionized water was added slowly. The solution was incubated at $98^{\circ} \mathrm{C}$ for $15 \mathrm{~min}$. Once the reaction was completed, $140 \mathrm{~mL}$ of deionized water and $\mathrm{H}_{2} \mathrm{O}_{2}(10 \mathrm{~mL}, 30 \%)$ were added to remove the excess $\mathrm{KMnO}_{4}$ and stirred for $40 \mathrm{~min}$. Finally, the resulting suspension was filtered and washed with $5 \% \mathrm{HCl}$ aqueous solution and $\mathrm{H}_{2} \mathrm{O}_{2}$ until the solution $\mathrm{pH}$ was $\sim 7$.
Finally, the GO solution was lyophilized and GO powder was obtained.

\section{Preparation of Pt-carbonyl complex/GO}

Briefly, $0.0372 \mathrm{~g}$ of $\mathrm{Na}_{2} \mathrm{PtCl}_{6} \cdot 6 \mathrm{H}_{2} \mathrm{O}(3.8 \mathrm{mmol}), 0.0728 \mathrm{~g}$ (27.9 mmol) of $\mathrm{CH}_{3} \mathrm{COONa} \cdot 3 \mathrm{H}_{2} \mathrm{O}$, and $10 \mathrm{~mL}$ of methanol were sequentially added to a $50-\mathrm{mL}$ three-neck flask. The flask was purged with highly pure nitrogen for $30 \mathrm{~min}$. Thereafter, the system was placed in a $\mathrm{CO}$ atmosphere, and the temperature was raised to $40^{\circ} \mathrm{C}$. After reaction for $24 \mathrm{~h}$, the solution turned chartreuse in color. Then, the desired amount of GO was added and the mixture was stirred for an additional $12 \mathrm{~h}$.

\section{Preparation of $\mathrm{Pt} / \mathrm{rGO}$ nanocatalysts of different sizes}

Pt clusters with controlled sizes loaded on rGO were prepared by removing the carbonyl group of the Pt-carbonyl complex over the temperature range of $150-200^{\circ} \mathrm{C}$ at different reaction times under a gentle flow of nitrogen gas. For example, Pt- $1.0 \mathrm{~nm} / \mathrm{rGO}$ could be prepared by decarbonylating at $150^{\circ} \mathrm{C}$ for $1 \mathrm{~h}$; Pt- $1.4 \mathrm{~nm} / \mathrm{rGO}$ was obtained at $2 \mathrm{~h} ; \mathrm{Pt}-1.7 \mathrm{~nm} / \mathrm{rGO}$ was prepared after reaction at $200^{\circ} \mathrm{C}$ for $2 \mathrm{~h}$; and Pt-2.4 nm/rGO was obtained at $4 \mathrm{~h}$. Finally, the as-prepared catalysts were separated by filtration and washed with ethanol and deionized water until no $\mathrm{Cl}^{-}$ions could be detected.

\section{Characterization}

The crystalline phase of the as-prepared samples was characterized by powder X-ray diffraction (XRD) using a Philips X' Pert diffractometer with $\mathrm{Cu}-\mathrm{Ka}$ radiation $(\lambda$ $=0.15418 \mathrm{~nm}$ ). The chemical state and composition of the products were analyzed using X-ray photoelectron spectroscopy (XPS, ESCALab250).Transmission electron microscopy (TEM) was performed using a JEM2100UHR transmission microscope equipped with an energy dispersive spectroscopy (EDS) detector (EDAX, JEOL, Japan). Infrared spectra were obtained using an IR spectrometer (Thermo-Nicole, NEXUS, USA). Raman spectra were recorded on a Raman spectrometer (DXR Microscope). Gas chromatography (GC) analysis was performed using an Agilent 3420A GC equipped with a KB-5 column and an FID detector.

\section{Catalytic performance evaluation}

In a typical procedure, $1.0 \mathrm{mmol}$ of the $\mathrm{NB}$ was dissolved in $6 \mathrm{~mL}$ of isopropanol and mixed with $1.0 \mathrm{mg}$ of the as-prepared nanocatalysts under 1 atm $\mathrm{H}_{2}$ at $25^{\circ} \mathrm{C}$. The reaction mixture was stirred at $900 \mathrm{rpm}$ at room temperature. After the reaction was complete, the mixture was separated 
by centrifugation, and the products were examined by gas chromatography (SP-3420A) with a 30 m capillary column (KB-5) using a flame ionization detector. The used catalysts were washed with isopropanol and collected at room temperature for performing the subsequent reactions.

\section{RESULTS AND DISCUSSION}

TEM images of Pt-1.0 nm/rGO with a loading of $40 \mathrm{wt} . \%$ $\mathrm{Pt}$ are shown in Fig. 1. The actual loading of Pt was determined by inductively coupled plasma mass spectrometry to be $39.1 \mathrm{wt} . \%$. The images clearly illustrate that the Pt clusters are homogeneously dispersed on the surface of the rGO sheets and have an average size of $1.0 \mathrm{~nm}$ with a narrow size distribution (Fig. 1a). The results indicate that $\mathrm{rGO}$ acts as an efficient support for the dispersion of uniform-sized Pt nanoclusters. The selected area electron diffraction (SAED) pattern in the inset of Fig. 1a further confirms the polycrystalline nature of Pt. Fig. 1b displays the HRTEM image of the Pt clusters dispersed on the rGO. The $d$-spacing of $\sim 0.226 \mathrm{~nm}$ corresponds to the (111) plane of the face-centered cubic $\mathrm{Pt}$, indicating that the clusters are well crystallized. High-angle annular dark field-scanning transmission electron microscopy (HAADF-STEM) imaging and the corresponding EDS mapping in Fig. 1c-e further show the good dispersion of $\mathrm{Pt}$ at a high loading on the rGO surface and the homogeneous distribution of elemental Pt and C. The formation process of Pt clusters is proposed as follows. The precursor $\left[\mathrm{Pt}_{3}(\mathrm{CO})_{6}\right]_{5}{ }^{2-}$ (Fig. S1) clusters possess a trigonal prism framework at low temperature [31]. Increasing the temperature, the compound clusters begin to convert to a larger cluster bounded by linear $\mathrm{C}=\mathrm{O}$ groups. The resulting carbonyl groups can be further desorbed by evacuation at $150^{\circ} \mathrm{C}$, leading to the formation of Pt nanoclusters. Furthermore, as shown in Fig. S2, all the absorption bands of $\mathrm{Pt} / \mathrm{rGO}$ belong to $\mathrm{rGO}$, revealing a clean surface of the nanoclusters. XRD was used to examine the crystalline structure of GO and Pt/rGO (Fig. S3). It is noted that a sharp diffraction peak appears at $10.8^{\circ}$ for pure GO, which is ascribed to the (002) plane of the graphene sheets of a few layers. After the formation of supported nanocatalysts, a new diffraction peak appeared at about $25^{\circ}$, implying the existence of stacking structures of
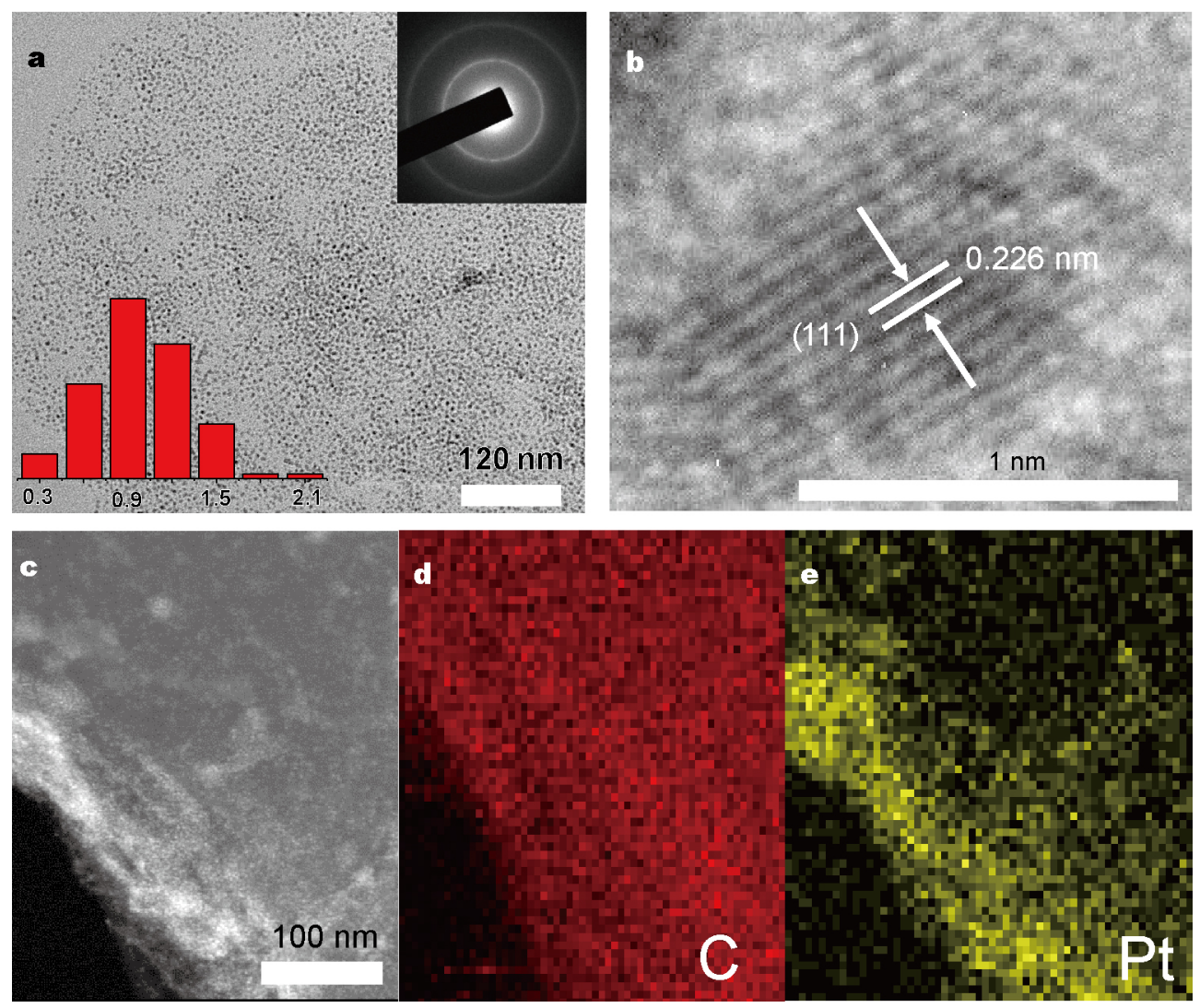

Figure 1 TEM image (a) and corresponding HRTEM image (b) of the Pt-1.0 nm/rGO nanocatalysts with 40 wt.\% of Pt. The insets in (a) show the Pt particle size distribution and the SAED pattern. (c-e) HAADF-STEM image and the corresponding EDX mapping of C and Pt. 
rGO [32]. Two characteristic diffraction peaks of (111) and (200) (JCPDS card 01-087-0642) are very broad, implying very small sizes of the sample.

Fig. 2 shows the representative TEM images and the corresponding particle size distributions of the $\mathrm{Pt} / \mathrm{rGO}$ catalysts. Highly dispersed Pt nanoclusters smaller than $3 \mathrm{~nm}$ were observed. The particle sizes seem uniform, and large particles are seldom detected. Statistical analysis of the particle size was performed by measuring $\sim 100 \mathrm{Pt}$ nanoparticles, which yielded the histograms shown in Fig. 2b, d, $\mathrm{f}$. It can be seen that the average size of the Pt nanoparticles is in the range of $1.4-2.4 \mathrm{~nm}$ at a temperature of $150-200^{\circ} \mathrm{C}$ after different reaction times. The higher the temperature and the longer the reaction time, the larger is the size of the obtained Pt nanoparticles. In addition, the size of the Pt nanoparticles on carbon supports is often related to the loading; that is, a higher loading usually results in the formation of larger Pt particles. In the case of $\mathrm{Pt} / \mathrm{rGO}$ with different sizes, the size of the Pt nanoparticles remains small despite the higher loading, which can be attributed to the strong anchoring effect of the oxygen-containing functional groups of the rGO.

The chemical composition and oxidation state of the as-prepared Pt-1 nm/rGO samples were identified by XPS (Fig. 3). The survey spectrum (Fig. 3a) shows the presence of carbon, oxygen, and platinum elements in the sample.
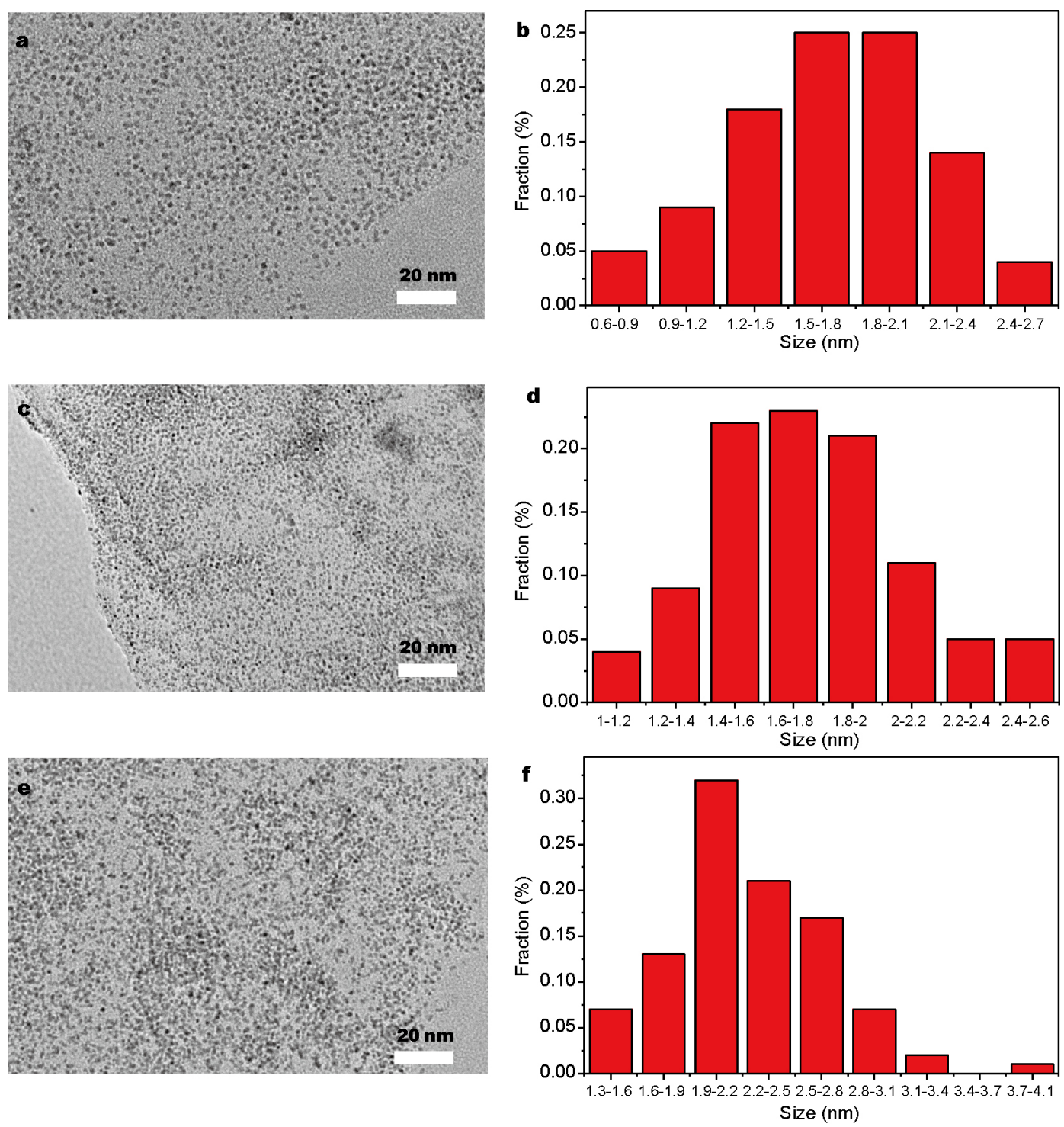

Figure 2 TEM images and size distributions of Pt/rGO obtained under different conditions: (a, b) Pt-1.4 nm/rGO with 40 wt.\% of Pt; (c, d) Pt-1.7 $\mathrm{nm} / \mathrm{rGO}$ with 40 wt.\% of Pt; (e, f) Pt-2.4 nm/rGO with $40 \mathrm{wt}$ \% of Pt. 

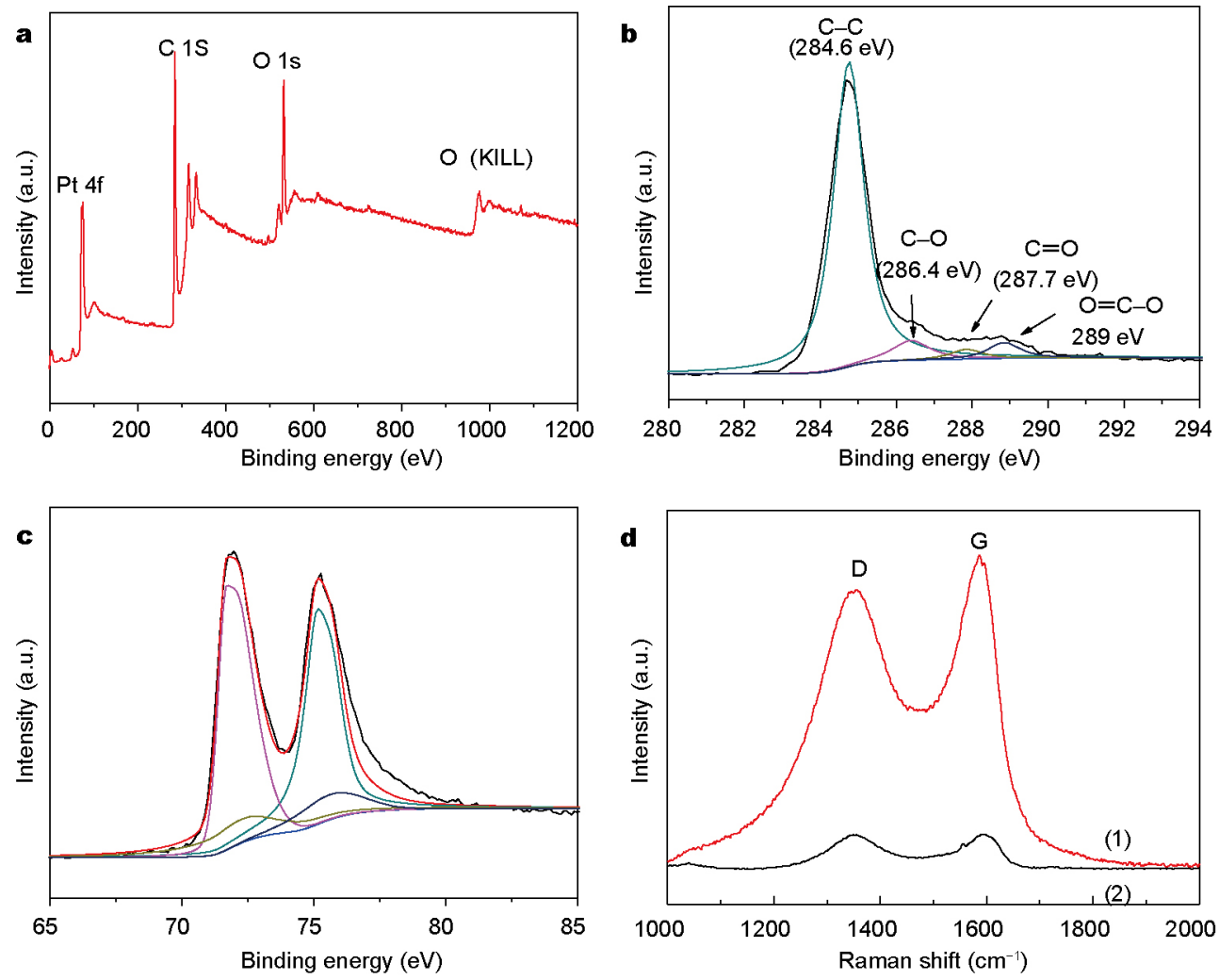

Figure 3 XPS of Pt-1 nm/rGO: (a) survey spectrum, (b) C 1s region, (c) Pt $4 \mathrm{f}$ region for Pt-1 nm/rGO. (d) Raman spectra of GO (1) and Pt-1 nm/rGO (2).

Fig. $3 \mathrm{~b}$ shows the high-resolution spectrum of $\mathrm{C} 1 \mathrm{~s}$, where four different carbon bonding states can be observed. The peak at $284.6 \mathrm{eV}$ was ascribed to the $\mathrm{C}-\mathrm{C}$ bond, whereas the signals at $286.4,287.8$, and $289.0 \mathrm{eV}$ were attributed to the $\mathrm{C}-\mathrm{OH}, \mathrm{C}=\mathrm{O}$, and $\mathrm{O}-\mathrm{C}=\mathrm{O}$ configurations, respectively [33]. Compared to the typical high-level oxidation state in GO, the product exhibited a sharp decrease in intensity, showing a significant loss of oxygen after thermal treatment. Fig. $3 \mathrm{c}$ shows the core-level XPS spectra of the $\mathrm{Pt} 4 \mathrm{f}$ region of the $\mathrm{Pt} / \mathrm{rGO}$ catalysts. The binding energy of the $\mathrm{Pt} 4 \mathrm{f}_{7 / 2}$ is $71.9 \mathrm{eV}$, with a shift of $1.2 \mathrm{eV}$ as compared to the binding energy of the standard metallic state $(70.7 \mathrm{eV})$ [34]. The peaks at $72.6\left(\mathrm{Pt}_{4 \mathrm{f}_{7 / 2}}\right)$ and $76.0 \mathrm{eV}\left(\mathrm{Pt} 4 \mathrm{f}_{5 / 2}\right) \mathrm{can}$ be assigned to $\mathrm{Pt}^{2+}$, owing to the oxygen linkages between the interfaces of the Pt clusters and the rGO, and the formation of oxide layers on the Pt surface. The shift suggests that the electron transfer may occur between the Pt nanoclusters and the oxygen of rGO. The high electronegativity of oxygen reduces the electron density of the Pt atoms and leads to electron-deficient states of the Pt nanoparticles in the $\mathrm{Pt} / \mathrm{rGO}$ catalyst. For the $\mathrm{Pt} / \mathrm{rGO}$ catalyst, about $88.5 \%$ of the Pt exists in the metallic state and $11.5 \%$ exists as $\mathrm{Pt}-\mathrm{O}-\mathrm{C}$.
In order to understand the conformational changes of carbon during the reaction, Raman spectra of GO and $\mathrm{Pt} / \mathrm{rGO}$ catalysts were obtained (Fig. 3d). The D band at $\sim 1350 \mathrm{~cm}^{-1}$ for GO and rGO is attributed to the disorder induced features caused by lattice defects. The $G$ band at $\sim 1587 \mathrm{~cm}^{-1}$ represents the in-plane vibration of symmetric $\mathrm{sp}^{2} \mathrm{C}-\mathrm{C}$ bonds [35]. Compared to the case of GO, the $\mathrm{D} / \mathrm{G}$ intensity ratio $\left(I_{\mathrm{D}} / I_{\mathrm{G}}\right)$ in the $\mathrm{Pt} / \mathrm{rGO}$ composites shows a slight increase $(0.90$ vs. 0.99$)$, which is indicative of a decrease in the average size of the $\mathrm{sp}^{2}$ domains [36]. The results confirm the reduction of GO by removing the carbonyl groups.

The catalytic performance of the obtained supported $\mathrm{Pt}$ nanoclusters was evaluated by the selective hydrogenation of $\mathrm{NB}$ at $25^{\circ} \mathrm{C}$ under $1 \mathrm{~atm} \mathrm{H}_{2}$. The results show nearly $100 \%$ yield of AN for the Pt/rGO nanocatalysts. To demonstrate the impact of the supports, the Pt-free rGO and pure Pt NPs (1 mg) were separately used to catalyze this reaction within $2 \mathrm{~h}$. The yield of AN was $0 \%$ and $8.18 \%$, respectively (Fig. 4a), demonstrating that the supports play an essential role in boosting the catalytic performance. Then, the Pt-1.0 $\mathrm{nm} / \mathrm{rGO}$ nanocatalysts with different loadings were used to catalyze the reaction. With the increased quantity of $\mathrm{Pt}$, the 

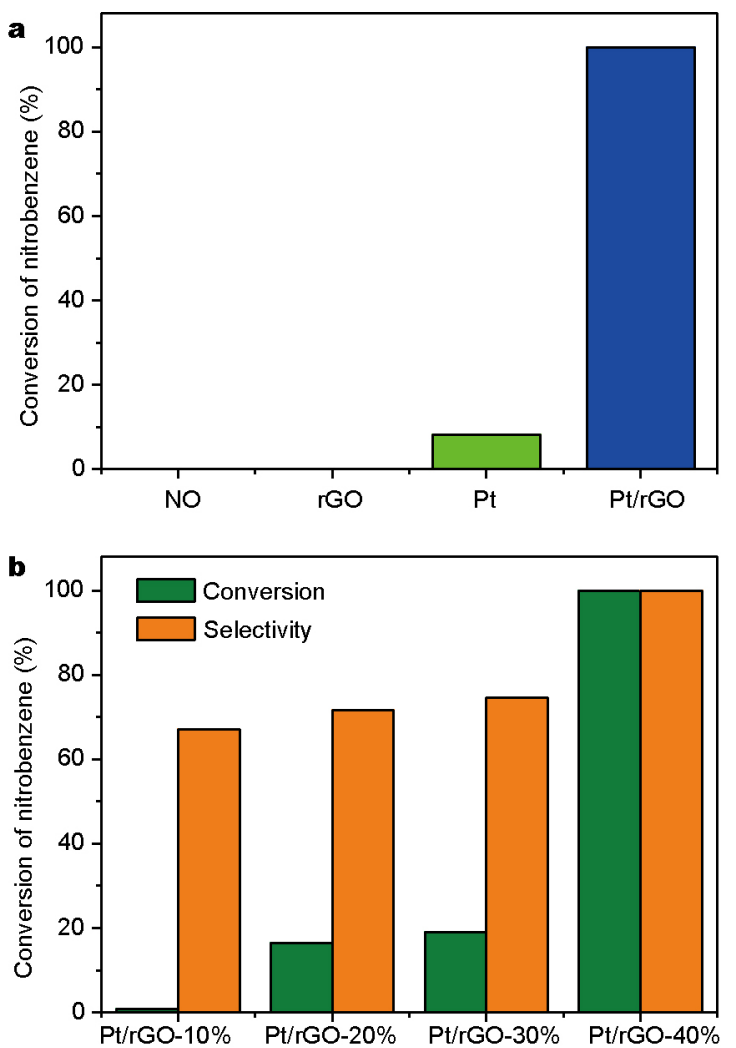

Figure 4 (a) Catalytic performance comparison of NB hydrogenation over the different catalysts in $2 \mathrm{~h}$. (b) Catalytic performance comparison over Pt-1.0 nm/rGO nanocatalysts with different Pt loadings in $2 \mathrm{~h}$.

conversion and selectivity of hydrogenation of $\mathrm{NB}$ also increased. The catalyst with $40 \mathrm{wt} . \% \mathrm{Pt}$ exhibits the best performance, associated with the complete conversion of NBand 100\% selectivity of AN within $2 \mathrm{~h}$ (Fig. 4b).

We also investigated the influence of the Pt cluster size on the catalytic activity. Fig. 5 shows a comparison of the hydrogenation conversion of NB catalyzed by $\mathrm{Pt} / \mathrm{rGO}$ nanocatalysts with $40 \mathrm{wt} . \% \mathrm{Pt}$ and different Pt cluster sizes. It was observed that Pt- $1 \mathrm{~nm} / \mathrm{rGO}$ achieved a $100 \%$ conversion ratio of $\mathrm{NB}$ to $\mathrm{AN}$ in 30 min together with a selectivity of $100 \%$. The turnover frequency (TOF) of Pt-1 nm/rGO (TOF: mol number of NB transformed per mol per h) reaches $975.4 \mathrm{~h}^{-1}$. This value is higher than the previously reported data for heterogeneously catalyzed dehydrogenation of $\mathrm{NB}[8,37,38]$. The conversion ratio is $81.55 \%$, $36.85 \%$, and $4.92 \%$ over Pt- $1.4 \mathrm{~nm} / \mathrm{rGO}$, Pt- $1.7 \mathrm{~nm} / \mathrm{rGO}$, and Pt-2.4 nm/rGO within the same reaction period, respectively; the corresponding TOFs are 796.5, 359.4, and $4.8 \mathrm{~h}^{-1}$. The conversion ratio on the Pt- $1 \mathrm{~nm} / \mathrm{rGO}$ sample is approximately 3 times higher than that on the Pt-1.7 $\mathrm{nm} / \mathrm{rGO}$, and over hundred fold higher than that on Pt-2.4
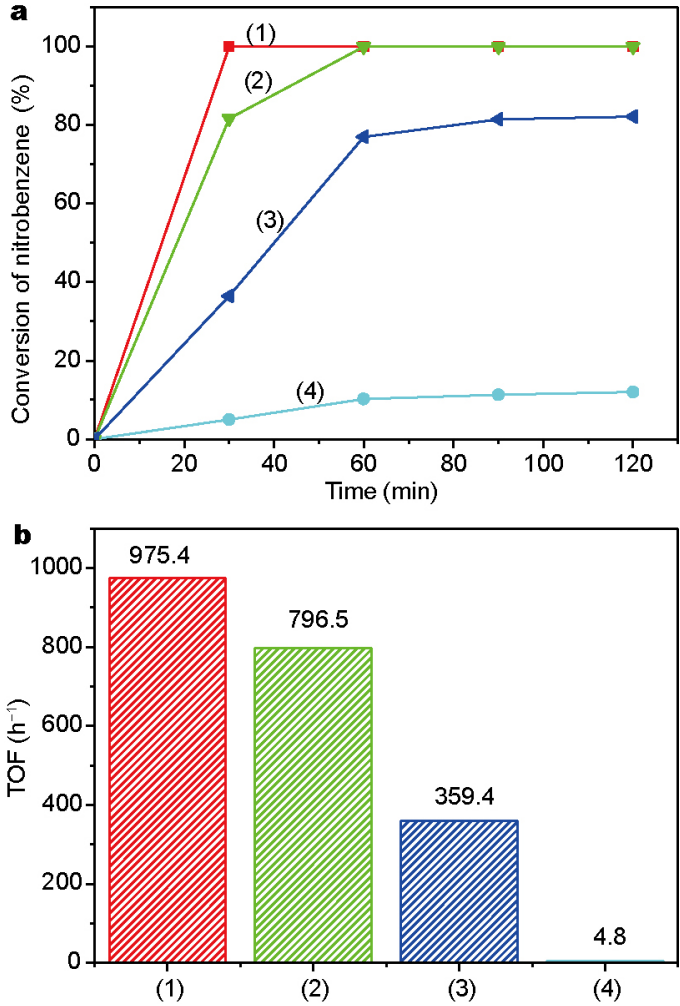

Figure 5 Conversion of NB during hydrogenation reactions (a) and the corresponding catalytic activity catalyzed by $\mathrm{Pt} / \mathrm{rGO}$ nanocatalysts with $40 \mathrm{wt} . \% \mathrm{Pt}$ and different Pt cluster sizes in $2 \mathrm{~h}$ (b). (1) Pt-1 nm /rGO, (2) Pt-1.4 nm/rGO, (3) Pt-1.7 nm/rGO, (4) Pt-2.4 nm/rGO.

$\mathrm{nm} / \mathrm{rGO}$. Even after the reaction was continued for $2 \mathrm{~h}$, the yield of AN was only $82.2 \%$ and $12.0 \%$ over Pt- $1.7 \mathrm{~nm} / \mathrm{rGO}$ and Pt- $2.4 \mathrm{~nm} / \mathrm{rGO}$, respectively. Apparently, the Pt cluster size has a strong influence on its catalytic activity for the hydrogenation of NB, which is in accordance with previous reports [39].

The enhancement in the NB hydrogenation can be summarized as three advantages of Pt/rGO: (1) the high dispersion of small $\mathrm{Pt}$ nanoclusters on the surface of rGO could provide rich active sites for the hydrogenation reaction, which not only improves the adsorption probability of the reactant molecules but also shortens the residence time of the reaction species, thus preventing over-hydrogenation [40]. (2) The Pt nanoclusters in the Pt/rGO catalysts provide an electron-deficient state, which is favorable for the adsorption of $\mathrm{H}_{2}$ [41]. As a result, more hydride ions are produced and the catalytic performance of the $\mathrm{Pt} / \mathrm{rGO}$ catalysts is enhanced. (3) The supported Pt nanoclusters were very "clean" because of the surfactant-free formation process (Fig. S2), allowing high catalytic activity in NB hydrogenation. 
In order to ascertain the catalytic reaction pathway, we analyzed the products obtained at different times. Fig. $6 \mathrm{a}$ shows the products of NB hydrogenation over the Pt-1 $\mathrm{nm} / \mathrm{rGO}$ nanocatalyst as the reaction proceeded. The results show that the intermediates only consist of NSB and PHA, and no other products are detected in the measurable range. The possible mechanism for AN formation from $\mathrm{NB}$ is shown in Fig. $6 \mathrm{~b}$ [42]. One route for AN production is that the NB is transformed into NSB and PHA successively in the hydrogen atmosphere, whose hydrogenation results in the formation of AN. The other route directly reduces NB to PHA without the production of intermediates. Owing to the rapid transformation of $\mathrm{NB}$ to $\mathrm{AN}$, and the relatively strong adsorption of NSB and PHA onto the surface of $\mathrm{Pt} / \mathrm{rGO}$, it is reasonable that the recombination of NSB and PHA over the catalysts was restrained, inhibiting the production of azoxybenzene or hydrazobenzene [43]. In addition, it is interesting that the concentration of NSB is higher than that of PHA in the reaction process, which also confirms the direct hydrogenation pathway.



b<smiles>Nc1ccc(-c2ccc(N=Cc3ccccc3[N+](=O)[O-])cc2)cc1</smiles>

Figure 6 (a) Reaction product profile of the NB hydrogenation over Pt-1 $\mathrm{nm} / \mathrm{rGO}$ catalysts under mild conditions; (b) proposed reaction pathway for the hydrogenation of $\mathrm{NB}$ over $\mathrm{Pt} / \mathrm{rGO}$ catalysts.

a
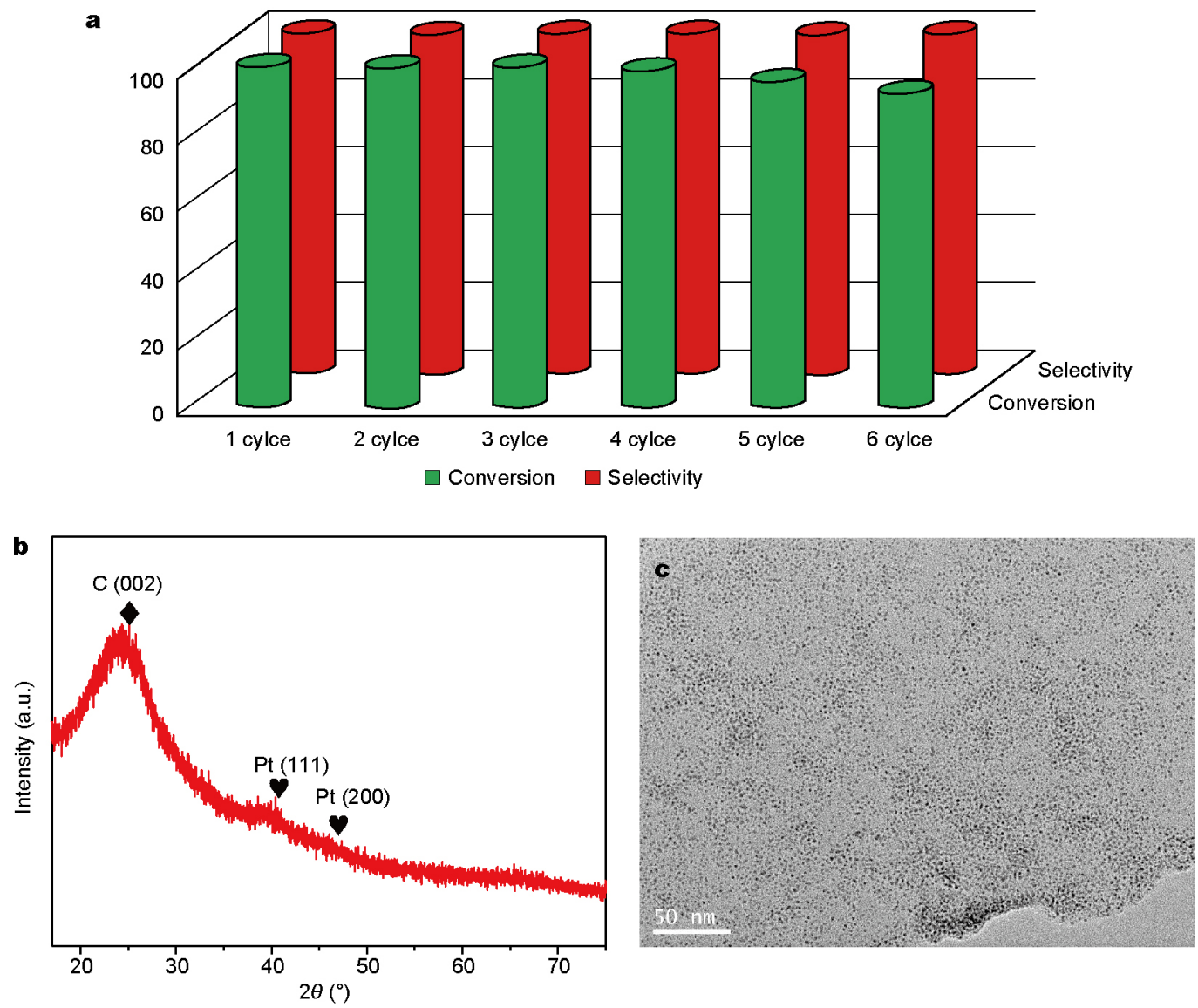

Figure 7 (a) Stability tests of the Pt-1 nm/rGO catalysts for hydrogenation of NB; (b, c) XRD and TEM image of the collected Pt-1 nm/rGO nanocatalysts after 6 cycles. 
For practical applications, the stability of a catalyst is also very important. A series of hydrogenation reactions with the recovered catalysts were performed. After the catalytic reaction was complete, the catalysts were collected by centrifugation and reused in the subsequent reactions. Because of the inevitable catalyst loss in the collection process, six cycles were performed. The results indicated that the conversion of NB remains at $92 \%$ even after six cycles (Fig. 7). Moreover, the morphology and microstructure of the used catalysts did not change significantly (Fig. 7b, c), implying its high stability.

\section{CONCLUSIONS}

In conclusion, a simple method was developed to prepare supported Pt nanoclusters with controlled sizes by thermal decomposition of the Pt carbonyl anions. The factors that affect the performance, such as dispersion and size of $\mathrm{Pt}$ clusters, were studied in detail for the catalytic hydrogenation of NB at room temperature under atmospheric conditions. The results indicate that $1 \mathrm{~nm}$ Pt clusters dispersed on the rGO exhibit the highest activity. It only takes $30 \mathrm{~min}$ to achieve $100 \%$ conversion and selectivity, and the TOF with respect to NB conversion is as high as $975.4 \mathrm{~h}^{-1}$. The origin of the high activity could be attributed to the synergistic effect of Pt clusters and rGO. Besides the support effect, the ultra-small size and the clean surface of the Pt clusters also contributed to the activity. The intermediate product analyses suggest the reaction pathway for the conversion of NB to AN follows a direct conversion route. It is expected that the specific synthetic approach can provide a promising avenue for the preparation of other metal-based heterogeneous nanocatalysts with unique sizes and excellent performance.

Received 13 October 2016; accepted 22 December 2016; published online 17 January 2017

1 Travis AS. Manufacture and uses of the anilines: a vast array of processes and products. In: Rappoport Z (ed.). The Chemistry of Anilines. West Sussex: John Wiley \& Sons, 2007, 715-782

2 Nishimura S. Handbook of Heterogeneous Catalytic Hydrogenation for Organic Synthesis. NewYork: John Wiley \& Sons, 2001, 332-336

3 Figueras F, Coq B. Hydrogenation and hydrogenolysis of nitro-, nitroso-, azo-, azoxy- and other nitrogen-containing compounds on palladium. J Mol Catal A-Chem, 2001, 173: 223-230

4 Fang J, Li J, Zhang B, et al. The support effect on the size and catalytic activity of thiolated $\mathrm{Au}_{25}$ nanoclusters as precatalysts. Nanoscale, 2015, 7: 6325-6333

5 Tomkins P, Gebauer-Henke E, Leitner W, et al. Concurrent hydrogenation of aromatic and nitro groups over carbon-supported ruthenium catalysts. ACS Catal, 2015, 5: 203-209

6 Mahata A, Rai RK, Choudhuri I, et al. Direct vs. indirect pathway for nitrobenzene reduction reaction on a $\mathrm{Ni}$ catalyst surface: a density functional study. Phys Chem Chem Phys, 2014, 16 : 26365-26374

7 Lin W, Cheng $\mathrm{H}$, Ming J, et al. Deactivation of $\mathrm{Ni} / \mathrm{TiO}_{2}$ catalyst in the hydrogenation of nitrobenzene in water and improvement in its stability by coating a layer of hydrophobic carbon. J Catal, 2012, 291: 149-154

8 Sheng B, Hu L, Yu T, et al. Highly-dispersed ultrafine Pt nanoparticles on graphene as effective hydrogenation catalysts. RSC Adv, 2012, 2: 5520-5523

9 Du W, Chen G, Nie R, et al. Highly dispersed Pt in MIL-101: an efficient catalyst for the hydrogenation of nitroarenes. Catal Commun, 2013, 41: 56-59

10 Grirrane A, Corma A, García H. Gold-catalyzed synthesis of aromatic azo compounds from anilines and nitroaromatics. Science, 2008, 322: 1661-1664

11 Chong H, Li P, Xiang J, et al. Design of an ultrasmall Au nanocluster- $\mathrm{CeO}_{2}$ mesoporous nanocomposite catalyst for nitrobenzene reduction. Nanoscale, 2013, 5: 7622-7628

12 Jagadeesh RV, Banerjee D, Arockiam PB, et al. Highly selective transfer hydrogenation of functionalised nitroarenes using cobaltbased nanocatalysts. Green Chem, 2015, 17: 898-902

13 Wisniak J, Klein M. Reduction of nitrobenzene to aniline. Ind Eng Chem Prod Res Dev, 1984, 23: 44-50

14 Fan X, Zhang G, Zhang F. Multiple roles of graphene in heterogeneous catalysis. Chem Soc Rev, 2015, 44: 3023-3035

15 Raccichini R, Varzi A, Passerini S, et al. The role of graphene for electrochemical energy storage. Nat Mater, 2014, 14: 271-279

16 Perreault F, Fonseca de Faria A, Elimelech M. Environmental applications of graphene-based nanomaterials. Chem Soc Rev, 2015, 44: 5861-5896

17 Ren H, Shao H, Zhang L, et al. Electrodes: a new graphdiyne nanosheet/Pt nanoparticle-based counter electrode material with enhanced catalytic activity for dye-sensitized solar cells. Adv Energ Mater, 2015, 5

18 Wen P, Gong P, Sun J, et al. Design and synthesis of Ni-MOF/CNT composites and $\mathrm{rGO} /$ carbon nitride composites for an asymmetric supercapacitor with high energy and power density. J Mater Chem A, 2015, 3: 13874-13883

19 Sun Z, Zhao Y, Xie Y, et al. The solvent-free selective hydrogenation of nitrobenzene to aniline: an unexpected catalytic activity of ultrafine Pt nanoparticles deposited on carbon nanotubes. Green Chem, 2010, 12: 1007

20 Nie R, Wang J, Wang L, et al. Platinum supported on reduced graphene oxide as a catalyst for hydrogenation of nitroarenes. Carbon, 2012, 50: 586-596

21 Lu P, Qiao B, Lu N, et al. Photochemical deposition of highly dispersed $\mathrm{Pt}$ nanoparticles on porous $\mathrm{CeO}_{2}$ nanofibers for the water-gas shift reaction. Adv Funct Mater, 2015, 25: 4153-4162

22 Wu G, Huang H, Chen X, et al. Facile synthesis of clean Pt nanoparticles supported on reduced graphene oxide composites: their growth mechanism and tuning of their methanol electro-catalytic oxidation property. Electrochim Acta, 2013, 111: 779-783

23 Chen D, Zhao X, Chen S, et al. One-pot fabrication of FePt/reduced graphene oxide composites as highly active and stable electrocatalysts for the oxygen reduction reaction. Carbon, 2014, 68: 755-762

24 Ikeda S, Ishino S, Harada T, et al. Ligand-free platinum nanoparticles encapsulated in a hollow porous carbon shell as a highly active heterogeneous hydrogenation catalyst. Angew Chem, 2006, 118 : 7221-7224

25 Nakamura J. The effect of a graphene support on the properties of Pt electrode catalysts in fuel cells. Carbon, 2015, 85: 443-444 
26 Galhenage RP, Xie K, Diao W, et al. Platinum-ruthenium bimetallic clusters on graphite: a comparison of vapor deposition and electroless deposition methods. Phys Chem Chem Phys, 2015, 17: 28354-28363

27 Kwak K, Tang Q, Kim M, et al. Interconversion between super-

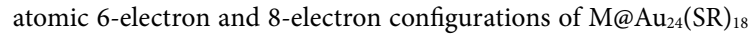
clusters (M = Pd, Pt). J Am Chem Soc, 2015, 137: 10833-10840

28 Imaoka T, Kitazawa H, Chun WJ, et al. Finding the most catalytically active platinum clusters with low atomicity. Angew Chem Int Ed, 2015, 54: 9810-9815

29 Zhang F, Jiao F, Pan X, et al. Tailoring the oxidation activity of $\mathrm{Pt}$ nanoclusters via encapsulation. ACS Catal, 2015, 5: 1381-1385

30 Hummers Jr. WS, Offeman RE. Preparation of graphitic oxide. J Am Chem Soc, 1958, 80: 1339-1339

31 Longoni G, Chini P. Synthesis and chemical characterization of platinum carbonyl dianions $\left[\mathrm{Pt}_{3}(\mathrm{CO})_{6}\right]_{n}{ }^{2-}(n=\sim 10,6,5,4,3,2,1)$. A new series of inorganic oligomers. J Am Chem Soc, 1976, 98: 7225-7231

32 Qiu JD, Wang GC, Liang RP, et al. Controllable deposition of platinum nanoparticles on graphene as an electrocatalyst for direct methanol fuel cells. J Phys Chem C, 2011, 115: 15639-15645

33 Tien HW, Huang YL, Yang SY, et al. The production of graphene nanosheets decorated with silver nanoparticles for use in transparent, conductive films. Carbon, 2011, 49: 1550-1560

34 Liang Y, Zhang $\mathrm{H}$, Zhong $\mathrm{H}$, et al. Preparation and characterization of carbon-supported PtRuIr catalyst with excellent CO-tolerant performance for proton-exchange membrane fuel cells. J Catal, 2006, 238: 468-476

35 Ferrari AC, Meyer JC, Scardaci V, et al. Raman spectrum of graphene and graphene layers. Phys Rev Lett, 2006, 97: 187401

36 Stankovich S, Dikin DA, Piner RD, et al. Synthesis of graphenebased nanosheets via chemical reduction of exfoliated graphite oxide. Carbon, 2007, 45: 1558-1565

37 Rode CV, Vaidya MJ, Jaganathan R, et al. Hydrogenation of nitrobenzene to $\mathrm{p}$-aminophenol in a four-phase reactor: reaction kinetics and mass transfer effects. Chem Eng Sci, 2001, 56: 1299-1304
38 Wu J, Ong SW, Kang HC, et al. Hydrogen adsorption on mixed platinum and nickel nanoclusters: the influence of cluster composition and graphene support. J Phys Chem C, 2010, 114: 21252-21261

39 Liang M, Wang X, Liu H, et al. Excellent catalytic properties over nanocomposite catalysts for selective hydrogenation of halonitrobenzenes. J Catal, 2008, 255: 335-342

40 Wang F, Liu J, Xu X. Layered material $\gamma$-ZrP supported platinum catalyst for liquid-phase reaction: a highly active and selective catalyst for hydrogenation of the nitro group in para-chloronitrobenzene. Chem Commun, 2008, 2040

41 Koningsberger D. In situ X-ray absorption spectroscopy as a unique tool for obtaining information on hydrogen binding sites and electronic structure of supported Pt catalysts: towards an understanding of the compensation relation in alkane hydrogenolysis. J Catal, 2003, 216: 178-191

42 Gelder EA, Jackson SD, Lok CM. The hydrogenation of nitrobenzene to aniline: a new mechanism. Chem Commun, 2005, 522

43 Corma A, Concepción P, Serna P. A different reaction pathway for the reduction of aromatic nitro compounds on gold catalysts. Angew Chem Int Ed, 2007, 46: 7266-7269

Acknowledgments This work was supported by the National Natural Science Foundation of China (51402362 and 21471160), Shandong Provincial Natural Science Foundation, China (ZR2014EMQ012 and ZR2016BM12), the Fundamental Research Funds for the Central Universities (15CX08010A,16CX05016 and 16CX05014A), and start-up fund from Tianjin University of Technology.

Author contributions Wei G designed and engineered the samples; Wei $\mathrm{G}$ wrote the manuscript with discussions with Zhao $\mathrm{X}, \mathrm{Du} \mathrm{K}$, and Wang Z. Liu J provided help in the characterization methods. An C and Zhang J supervised the projects and carefully reviewed and modified this manuscript. All authors contributed to the general discussion.

Conflict of interest The authors declare that they have no conflict of interest.

Supplementary information Supplementary data are available in the online version of the paper. 

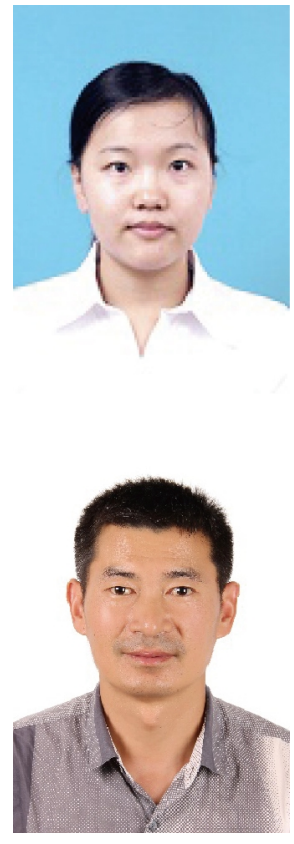

Guijuan Wei graduated from the School of Chemistry and Materials Science, Ludong University in 2013. She is currently a PhD candidate at China University of Petroleum (UPC) with Prof. Changhua An. Her research interests include the synthesis, characterization, and explorations of efficient catalysts in the fields of clean energy production and environmental purification.
Changhua An received his PhD degree from the University of Science and Technology of China (USTC) in 2003 with Prof. Yitai Qian. He has been a full professor of materials science and chemistry since 2013 at UPC. He joined Tianjin University of Technology as a professor in Nov. 2016. His research interests are the synthesis, characterization, and exploration of efficient catalysts in the fields of clean energy production and environmental purification.

\section{原位热解羰基铂制备性能优越的负载型铂纳米团簇}

魏桂涓 ${ }^{1,2}$, 赵西夏 ${ }^{1}$, 安长华 ${ }^{1,2^{*}}$, 刘俊学 ${ }^{1}$, 王兆㷊 ${ }^{1}$, 杜坤 $^{1}$, 张军 $^{1 *}$

摘要 本文以羰基铂为前驱体, 采用简便的原位热解方法, 成功地合成了负载在还原氧化石墨烯( $\mathrm{rGO}$ )纳米片上的直径为 $1.0-2.4 \mathrm{~nm}$ 的清洁 $\mathrm{Pt}$ 纳米团簇. 由于 $\mathrm{Pt}$ 纳米团簇和 $\mathrm{rGO}$ 片之间的电子转移, 所制备的负载 $\mathrm{Pt}$ 纳米团簇处于缺电子状态. 在 $25^{\circ} \mathrm{C} 、 1 \mathrm{~atm}$, 制备的 $\mathrm{Pt}$ 纳米团簇 $-1 \mathrm{~nm} / \mathrm{rGO}$ 催化剂的硝基苯选择性加氢的转换频率(TOF)达到 $975.4 \mathrm{~h}^{-1}$. 这个数值是目前硝基苯的非均相催化氢化所报道的活性最高值. 此 外, 根据中间产物分析, Pt-1 nm/rGO催化硝基苯加氢的机理是直接氢化. 这项工作在构筑高效催化剂方面提供了一个简单有效的途径, 并 且可以进一步扩展制备其他具有超小尺寸和卓越性能的金属催化剂. 